University of South Florida

DIGITAL COMMONS

Digital Commons @ University of

@ UNIVERSITY OF SOUTH FLORIDA

South Florida

7-20-1985

\title{
On the Response of the Equatorial Thermocline in the Atlantic Ocean to the Seasonally Varying Trade Winds
}

\author{
Robert H. Weisberg \\ University of South Florida, weisberg@usf.edu \\ T. Y. Tang \\ University of South Florida
}

Follow this and additional works at: https://digitalcommons.usf.edu/msc_facpub

Part of the Marine Biology Commons

\section{Scholar Commons Citation}

Weisberg, Robert H. and Tang, T. Y., "On the Response of the Equatorial Thermocline in the Atlantic Ocean to the Seasonally Varying Trade Winds" (1985). Marine Science Faculty Publications. 86.

https://digitalcommons.usf.edu/msc_facpub/86

This Article is brought to you for free and open access by the College of Marine Science at Digital Commons @ University of South Florida. It has been accepted for inclusion in Marine Science Faculty Publications by an authorized administrator of Digital Commons @ University of South Florida. For more information, please contact digitalcommons@usf.edu. 


\title{
On the Response of the Equatorial Thermocline in the Atlantic Ocean to the Seasonally Varying Trade Winds
}

\author{
R. H. Weisberg AND T. Y. TANG \\ Department of Marine Science, University of South Florida, St. Petersburg
}

\begin{abstract}
Measurements made during the Seasonal Response of the Equatorial Atlantic experiment in 1983, when the easterly trade winds near the equator ceased and then intensified as part of their annual cycle, show a sequence of events leading to an adjusted thermocline. Both the duration and extent of the downwelling and upwelling associated with the adjustment process were zonally inhomogeneous along the equator. An analytical reduced gravity model was driven by a hierarchy of easterly wind stress forcing functions representative of the Atlantic to compare the integral nature of the forced longwave responses with the observations. Qualitative agreement was found with upwelling and downwelling sequences within the forced region increasing to the east as observed. Apparent model propagation speeds differed significantly from the prescribed model wave speeds within the forced region owing to the growth parameters of the winds, and boundary reflections distorted the responses to the east of the forced region. The resulting interference patterns tended to separate the region $0^{\circ}-10^{\circ} \mathrm{W}$ along the equator from the African coast as one of maximum upwelling.
\end{abstract}

\section{INTRODUCTION}

The sudden onset of easterly or westerly winds upon an equatorial ocean will produce accelerating currents accompanied by upwelling or downwelling [e.g., Yoshida, 1959; $O$ 'Brien and Hurlburt, 1974]. These currents and their attendant vertical motions reach equilibrium after wave fronts emanating from the boundaries of either the windforced region or the ocean basin bring the zonal pressure gradient into balance with the wind stress [e.g., Moore and Philander, 1977]. Solutions to this initial value problem may be obtained by projecting the wind stress forcing function onto the ocean's equatorial wave modes and then integrating these projections with time, a formulation for which is given by Cane and Sarachik [1976, 1977] for both unbounded and bounded ocean basins.

Measurements made during the Seasonal Response of the Equatorial Atlantic (SEQUAL) experiment in 1983, when the easterly trade winds near the equator ceased and then intensified as part of their annual cycle [Garzoli and Katz, 1984], show the sequence of events leading to a seasonally adjusted thermocline and pressure gradient along the equator in the Atlantic Ocean [Katz, 1984; Weisberg, 1984] during that year. The purpose of the present paper is to compare these observations with calculations of the thermocline's response to idealized winds using a linear long-wave model. We seek to demonstrate a consistency between the observations and the analytical results and to discuss the integral nature of the responses to both decreasing and increasing easterly wind stress.

The paper is organized into six sections. Section 2 presents the pertinent oceanic data gathered in 1983. Downwelling and upwelling sequences were observed to be zonally inhomogeneous increasing eastward in both duration and magnitude over the central equatorial Atlantic. This observational finding motivated the analytical study which follows in section 3, where the thermocline responses to idealized intensifying easterly wind stress distributions are calculated

Copyright 1985 by the American Geophysical Union.

Paper number $5 \mathrm{C} 0248$.

$0148-0227 / 85 / 005 C-0248 \$ 05.00$ along the equator as initial value problems. We use a linear, adiabatic, equatorial $\beta$ plane, reduced gravity model similar to that of Cane and Sarachik [1976, 1977]. To establish our arguments on a conceptual basis, we present solutions for an unbounded basin, a western bounded basin, and a western and eastern bounded basin and discuss their evolution in turn. One finding is that the character of the thermocline response is dependent upon longitudinal position relative to both the domain of the forcing and the ocean's boundaries in a manner qualitatively similar to what was observed. A second finding is that reflections from the eastern boundary distort the response emanating from the forced region before it has time to develop fully. Consequently, for annual scale forcing, the propagation of nondispersive free wave pulses without change in form is impossible in the Atlantic, as the basin is simply too small. Section 4 changes the initial development of the solutions in section 3 by allowing the easterly winds to relax first before they intensify. The results agree qualitatively with the downwelling/upwelling/downwelling sequences observed during 1983. A third finding is that the interference between the relaxation and subsequent intensification responses alters the apparent propagation speed of these sequences along the equator. In the Gulf of Guinea the interference patterns tend to separate the region around $0^{\circ}-10^{\circ} \mathrm{W}$ from the African coast as one of maximum upwelling. Section 5 discusses these findings, and section 6 provides a summary.

\section{Equatorial atlantic Observations DURING 1983}

The surface wind stress over the equatorial Atlantic Ocean varies annually with the latitudinal migration of the Intertropical Convergence Zone (ITCZ). Weakest trade winds near the equator occur in boreal spring when the ITCZ intercepts it, and strongest (southeast) trade winds occur in summer and fall when the ITCZ is positioned north of it. Descriptive climatologies of the region are provided by Hastenrath and Lamb [1977] and Hellerman [1979]. Since the southeast trade winds over the equatorial Atlantic veer more easterly with increasing longitude, easterly wind stress increases from around zero between $0^{\circ} \mathrm{W}$ and $10^{\circ} \mathrm{W}$ to a maximum at the Brazilian coast. 


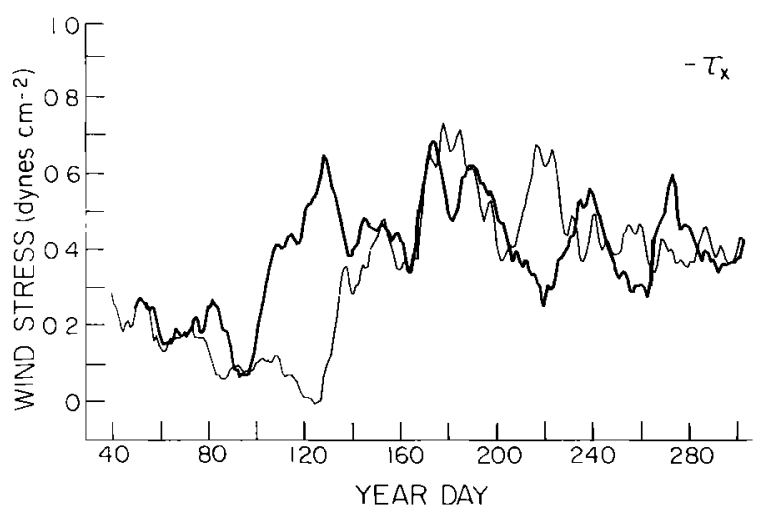

Fig. 1. Easterly component of wind stress measured at St. Peter and Paul Rocks during 1983 (bold line) and 1979 (light line) from Garzoli and Katz [1984].

Direct time series observations during 1979 and 1983 from St. Peter and Paul Rocks located at $1^{\circ} \mathrm{N}, 29^{\circ} \mathrm{W}$ by Garzoli and Katz [1984] demonstrate that the springtime transition from weak to strong easterlies can occur quite rapidly. As shown in Figure 1, the surface winds during the first year of the SEQUAL experiment in 1983 underwent a final relaxation event over approximately 10 days before intensifying to their maximum value over aproximately the next 30 days. With the exception of a phase lag, the behavior during 1979 was very similar in its rapid transition from weak to strong winds. Simultaneous measurements from moored buoys along the equator by Payne [1984] further showed that the relaxation/intensification event during 1983 occurred nearly simultaneously over a large portion of the central equatorial Atlantic.

The response of the thermocline to the observed wind stress variations during 1983 can be inferred using bottom mounted inverted echo sounder (IES) records and temperature time series from surface moorings obtained during SEQUAL. Figure 2 from Katz [1984] shows acoustic travel time series from IES's located along the equator between $38^{\circ} \mathrm{W}$ and $10^{\circ} \mathrm{W}$. A decrease (increase) in travel time can be related to downwelling (upwelling). Coincident with the relaxation and intensification of the wind stress is a sequence of downwelling followed by upwelling and then downwelling again. The initial downwelling and upwelling event has the appearance of moving eastward as well as being more pronounced to the east. Also the upwelling occurs over a longer duration to the east before finally giving way to downwelling. Figure 3 shows temperature time series within the thermocline on the equator at $28^{\circ} \mathrm{W}$ and $15^{\circ} \mathrm{W}$ from Weisberg $[19 \mathrm{~d} f]$. Beginning at the end of March and coincident with the final wind stress relaxation is a downwelling of the thermocline which starts out nearly simultaneously at $28^{\circ} \mathrm{W}$ and $15^{\circ} \mathrm{W}$. This event peaks during the second week of April at $28^{\circ} \mathrm{W}$ after which the thermocline upwells, with the onset of upwelling nearly coincident with the increase in easterly wind stress. Smoothing out the higher-frequency variability, we observe that the downwelling at $15^{\circ} \mathrm{W}$ occurs over a longer duration than at $28^{\circ} \mathrm{W}$ again yielding the appearance of eastward propagation. Upwelling begins a little later at $15^{\circ} \mathrm{W}$ than at $28^{\circ} \mathrm{W}$ and it lasts longer. Following the upwelling at both longitudes is a downwelling which eventually leads to what appears to be a relatively steady state. Although the general form of the temperature time series at both longitudes is similar, what sets them apart is the zonal inhomogeneity in both the duration and the extent of the downwelling and upwelling. Sequences of variability last longer and generally have larger magnitude at points further east.

The observed zonal inhomogeneity suggests that free wave analyses alone are not applicable here, so in the next section we will attempt to understand the general character of the observations by analyzing the forced response of an equatorial ocean basin both within and outside the domain of easterly wind stress forcing. The general character of the data presented will be shown to be consistent with a forced integral response.

\section{Analytical Results}

A linear, adiabatic, equatorial $\beta$ plane, reduced gravity model fashioned after Cane and Sarachik $[1976,1977]$ and as applied by Weisberg and Tang [1983] and Tang and Weis-

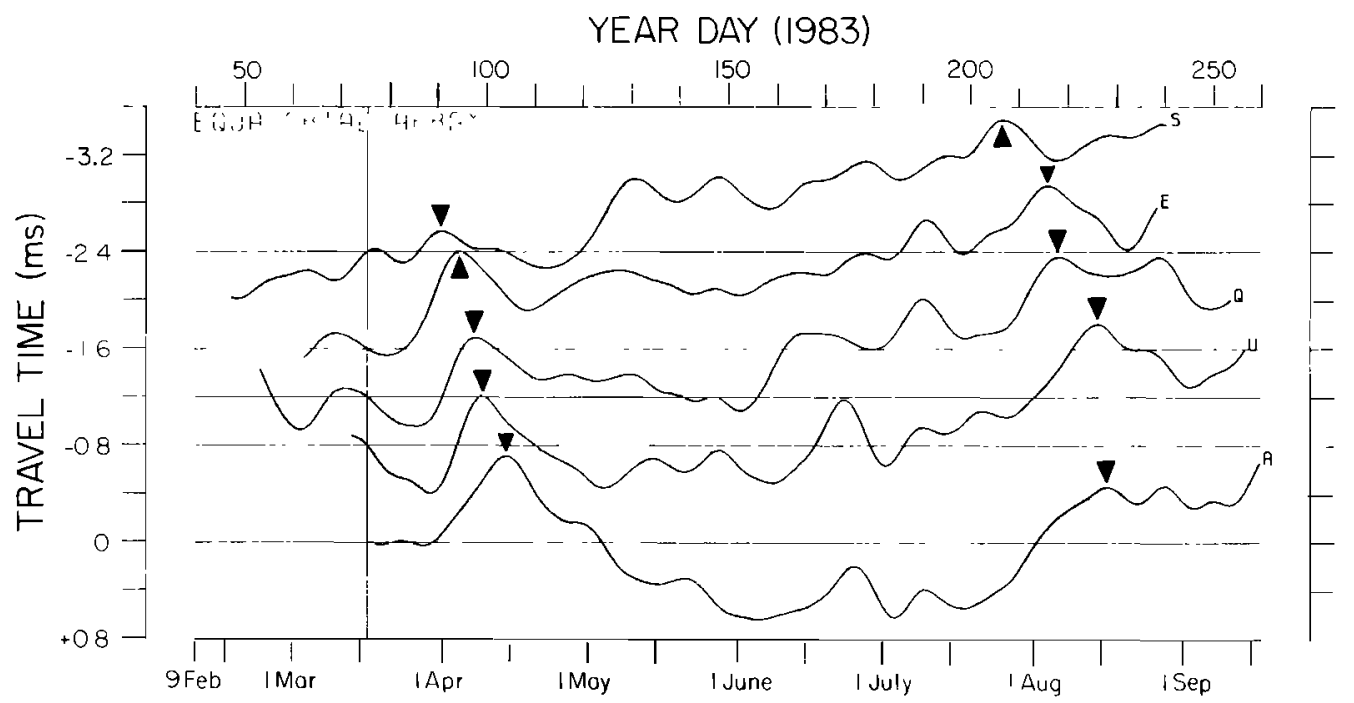

Fig. 2. Relative acoustic travel time from inverted echo sounders positioned along the equator at $38^{\circ} \mathrm{W}$ (top), $34^{\circ} \mathrm{W}$, $28^{\circ} \mathrm{W}, 20^{\circ} \mathrm{W}$, and $10^{\circ} \mathrm{W}$ (bottom). A $1-\mathrm{ms}$ change in travel time is roughly equivalent to a 20 -m displacement of the thermocline. The figure and travel time to thermocline displacement conversion are from Katz [1984]. 


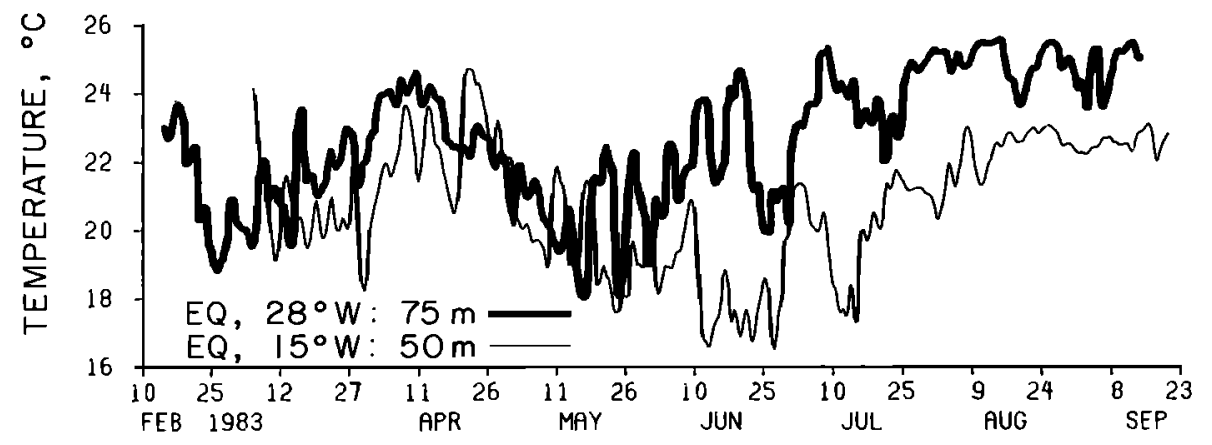

Fig. 3. Temperature time series from within the thermocline on the equator at $28^{\circ} \mathrm{W}$ and $15^{\circ} \mathrm{W}$ from Weisberg [1984].

berg [1984] is forced from a state of rest by temporally and spatially varying easterly wind stress distributions. The ocean response is calculated by Fourier transforming the equations of motion, projecting the forcing function onto the appropriate equatorial wave modes of the homogeneous equations, integrating in time, and then inverting the Fourier transforms using a long-wave approximation. Since the response is an integral of a particular forcing function, its details depend upon the zonal and temporal forms of the forcing function. We begin with the simplest applicable forcing function, a uniform bounded easterly wind stress switched on at time $t=0$ as shown in Figure $4 a$. Since the wind over the equatorial Atlantic is neither uniform nor instantaneously switched on, we then consider winds that increase linearly with time to a steady value (also shown in Figure $4 a$ ) and winds that increase linearly both in space and time as shown in Figure $4 b$. The latter is a simplistic characterization of the zonal wind stress along the equator in the Atlantic Ocean which increases from zero between $0^{\circ} \mathrm{W}$ and $10^{\circ} \mathrm{W}$ to a maximum at the Brazilian coast. The total response consists of a directly forced part plus boundary reflections. For simplicity, the meridional distribution of easterly wind stress is chosen to be normal, so it forces only an equatorial Kelvin wave and a first meridional mode Rossby wave. This is a special case having significant off equatorial ramification but with relatively little effect upon the evolution of the thermocline displacement directly on the equator [e.g., Cane and Sarachik, 1976; Weisberg and Tang, 1983]. Upon reaching the eastern boundary, Kelvin waves reflect as the sum of higher-mode Rossby waves, so these eventually enter into the total solution where applicable. To observe how the forced response and reflected waves affect the overall character of the solutions, we consider basins that are unbounded, bounded at the west only, and bounded at both the west and the east.

Common to all of the cases will be a reduced gravity Kelvin wave speed of $1.6 \mathrm{~m} / \mathrm{s}$ (as estimated using the depth of the thermocline and the density difference across it) and a zonal wind fetch of $4500 \mathrm{~km}$ extending from $5^{\circ} \mathrm{W}$ to $46^{\circ} \mathrm{W}$. For bounded basin calculations the western and eastern
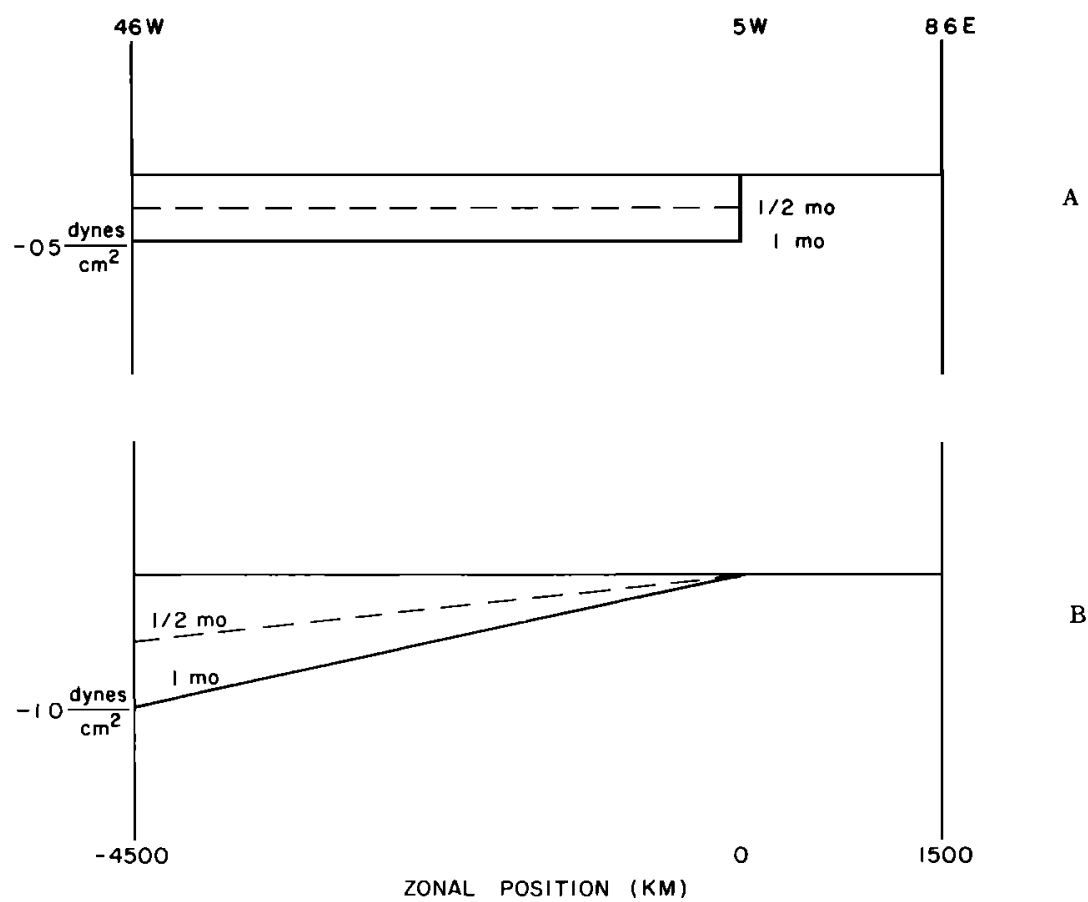

Fig. 4. Model geometry and easterly wind stress forcing functions for $(a)$ zonally uniform winds switched on instantaneously or allowed to grow linearly with time for 1 month and $(b)$ winds increasing linearly to the west and linearly with time for 1 month. 


\section{UNBOUNDED}

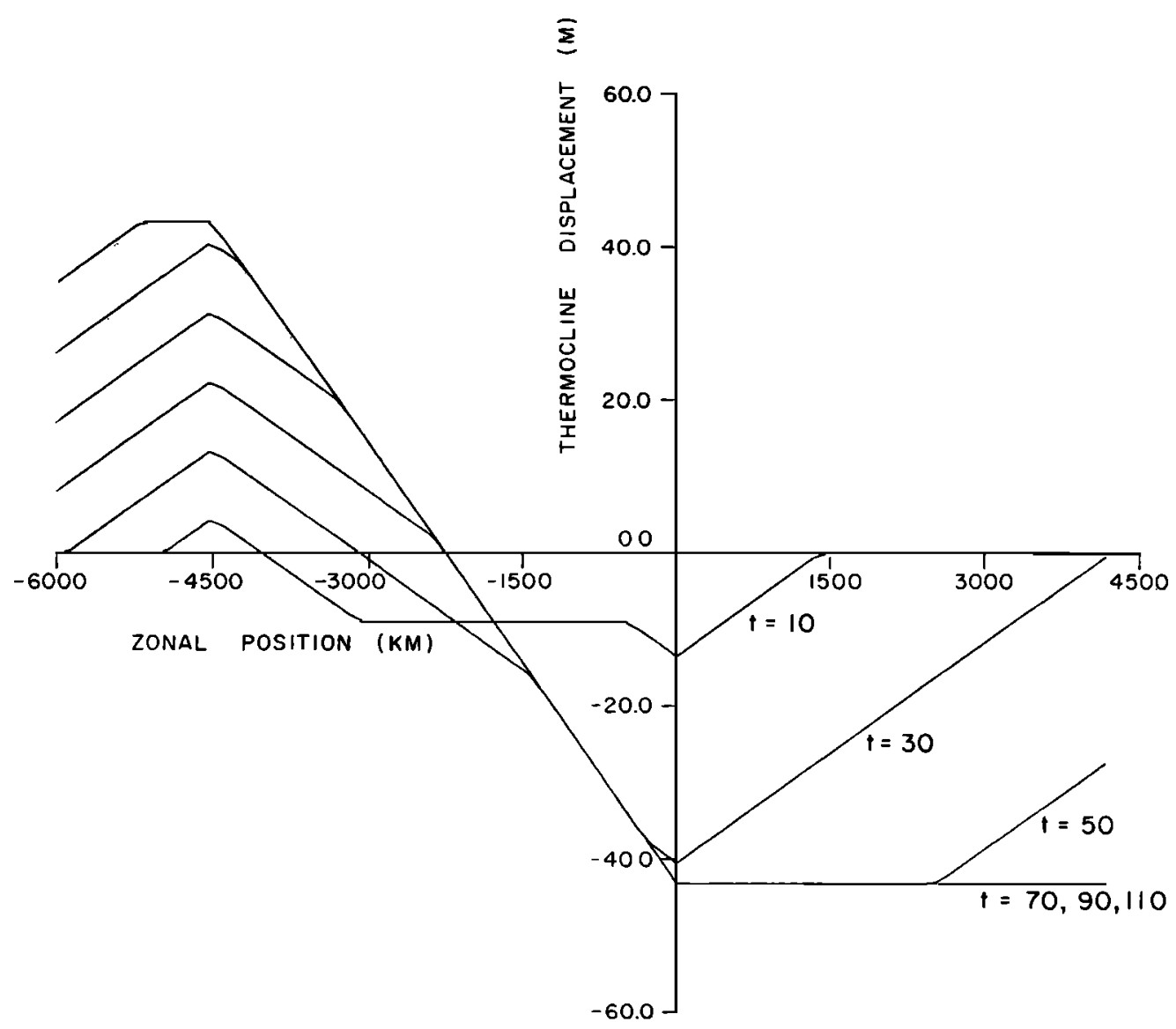

Fig. 5. Thermocline displacement in meters as a function of zonal position along the equator in kilometers at successive times after the onset of easterlies switched on uniformly between the origin and $-4500 \mathrm{~km}$ in an unbounded basin. Negative displacement corresponds to a decreasing upper layer or upwelling.

boundaries will be positioned at $46^{\circ} \mathrm{W}$ and $8.6^{\circ} \mathrm{E}$ for a total basin width of $6000 \mathrm{~km}$. Time series of thermocline displacement will be sampled at $28^{\circ} \mathrm{W}, 15^{\circ} \mathrm{W}, 5^{\circ} \mathrm{W}$ and $0^{\circ} \mathrm{W}$.

\section{Case A: Uniform Easterly Wind Stress} Switched on at $t=0$

The analytical form of the forcing function is

$$
\tau(x, y, t)=r \exp \left(-y^{2} / 2\right)[H(x)-H(x+L)] H(t)
$$

where the $H$ 's are step functions and $r$ and $L$ are the nondimensional amplitude and fetch of the easterlies, respectively. Values of $r=0.039$ and $L=16.81$ correspond to $0.5 \mathrm{dyn} / \mathrm{cm}^{2}$ and $4500 \mathrm{~km}$, respectively.

As the simplest of the cases considered, we will review the development of the response to this particular forcing function in detail to facilitate discussion of the more complex forcing functions to follow. Related discussions may be found, for example, in papers by Hurlburt et al. [1976], McCreary [1976], Cane and Sarachik [1977], and Philander and Pacanowski [1980]. Figure 5 shows the perturbation of the thermocline along the equator as a function of longitude for an unbounded basin at successive times. Negative values correspond to a decrease in upper layer thickness or upwelling. Similarly, positive values correspond to downwelling. Instantaneous with the onset of the wind stress is a westward accelerating jet and upwelling on the equator. Initially, the upwelling occurs uniformly with longitude away from the boundaries of the forced region as in the Yoshida [1959] case. Wave fronts propagate both away from the forced region and into its center in order to bring the oceanic pressure gradient in balance with the wind stress. In the present case, nondispersive Kelvin waves propagate eastward from both extremities while first meridional mode nondispersive Rossby waves propagate westward. When these two wave fronts meet, the pressure gradient attains the adjusted state as shown in Figure 5. Wave energy continues to propagate away from the forced region, which ultimately leads to a flat thermocline outside the forced region with this final state in the west lagging that in the east, since firstmode Rossby waves travel at only one-third the speed of the Kelvin waves. The final state shows the thermocline displaced upward at the eastern end of the forced region by the same amount it is displaced downward at the western end and with a node at the center. The central position of the node is a feature specific to the normally distributed wind stress, since the meridional distribution in this case determines the relative projections onto Kelvin and Rossby waves and consequently the meridional mass and heat flux within the forced region. The position of the nodal point may be calculated from the Kelvin wave projection alone as this is the only wave existing at the eastern terminus of the forced region. For Gaussian distributed zonal wind stress with standard deviation $\sigma$, the Kelvin wave upper layer thickness perturbation $h_{k}(x, y, t)$ is given by 


\section{WESTERN BOUNDARY}

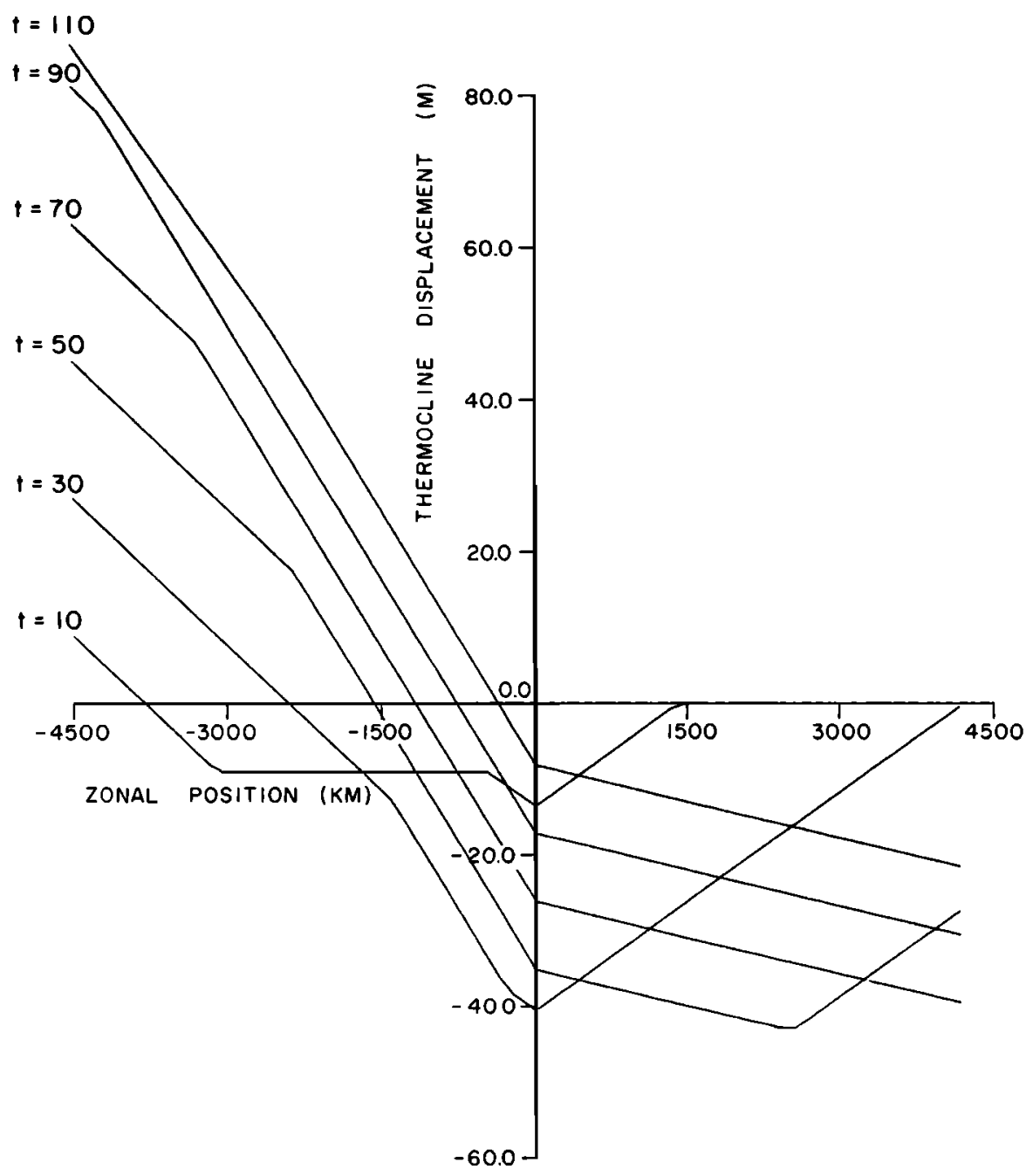

Fig. 6. Same as Figure 5 but with a western boundary at $-4500 \mathrm{~km}$.

$$
\begin{gathered}
h_{k}(x, y, t)=\frac{r 2^{1 / 2} \pi^{1 / 4}}{2\left(1+\sigma^{-2}\right)^{1 / 2}} \psi_{0}(y)[x H(x)-(x-t) H(x-t) \\
-(x+L) H(x+L)+(x-t+L) H(x-t+L)]
\end{gathered}
$$

where $\psi_{0}(y)$ is the Hermite function of zeroth order equalling $\pi^{-1 / 4}$ at $y=0$. Thus the Kelvin wave upper layer thickness perturbation evaluated at $x=0, y=0$, and $t>L$ (or dimensional $t>L / c$ where $c$ is the Kelvin wave speed) is

$$
h_{k}(0,0, t>L)=-r L 2^{-1 / 2}\left(1+\sigma^{-2}\right)^{-1 / 2}
$$

With the steady state slope equalling $-r$, the distance $d$ of the nodal point from the eastern terminus of the forced region is

$$
d=L 2^{-1 / 2}\left(1+\sigma^{-2}\right)^{-1 / 2}
$$

so for the special case considered here $(\sigma=1), d=L / 2$ while for meridionally uniform winds $(\sigma=0) d=2^{1 / 2} L / 2$. This dependence of the nodal point on the meridional distribution of zonal wind stress is of relevance to seasonal heat transport studies such as Cane and Sarachik [1983].

Addition of a western boundary at that extreme of the forced region modifies the thermocline development, since the forced Rossby wave response reflects as a Kelvin wave as shown in Figure 6. Both the forced first-mode Rossby wave and its western boundary reflected Kelvin wave are downwelling waves. Therefore the thermocline slope develops more rapidly in the west in the presence of a boundary there. Also the reflected Kelvin wave eventually counters the upwelling to the east of the forced region resulting in a final state of zero displacement there which differs from the unbounded result of Figure 5.

Addition of an eastern boundary further complicates the thermocline development, since the forced and reflected Kelvin waves reflect at the eastern boundary as a sum of higher meridional mode Rossby waves. This development is shown in Figure 7. Since each reflection begets new reflections, a final state of equilibrium with pressure gradient in the forced region balancing wind stress there and with a flat thermocline to the east of the forced region develops much more slowly and the final displacement of the thermocline in the east depends upon the scale of the forced region relative to the scale of the ocean basin. Although the overall character of the thermocline slope is attained after the primary reflections of the forced response transverse the basin, successively smaller perturbations to the thermocline slope continue indefinitely in the absence of dissipation.

Having shown the sequence of events leading to an 


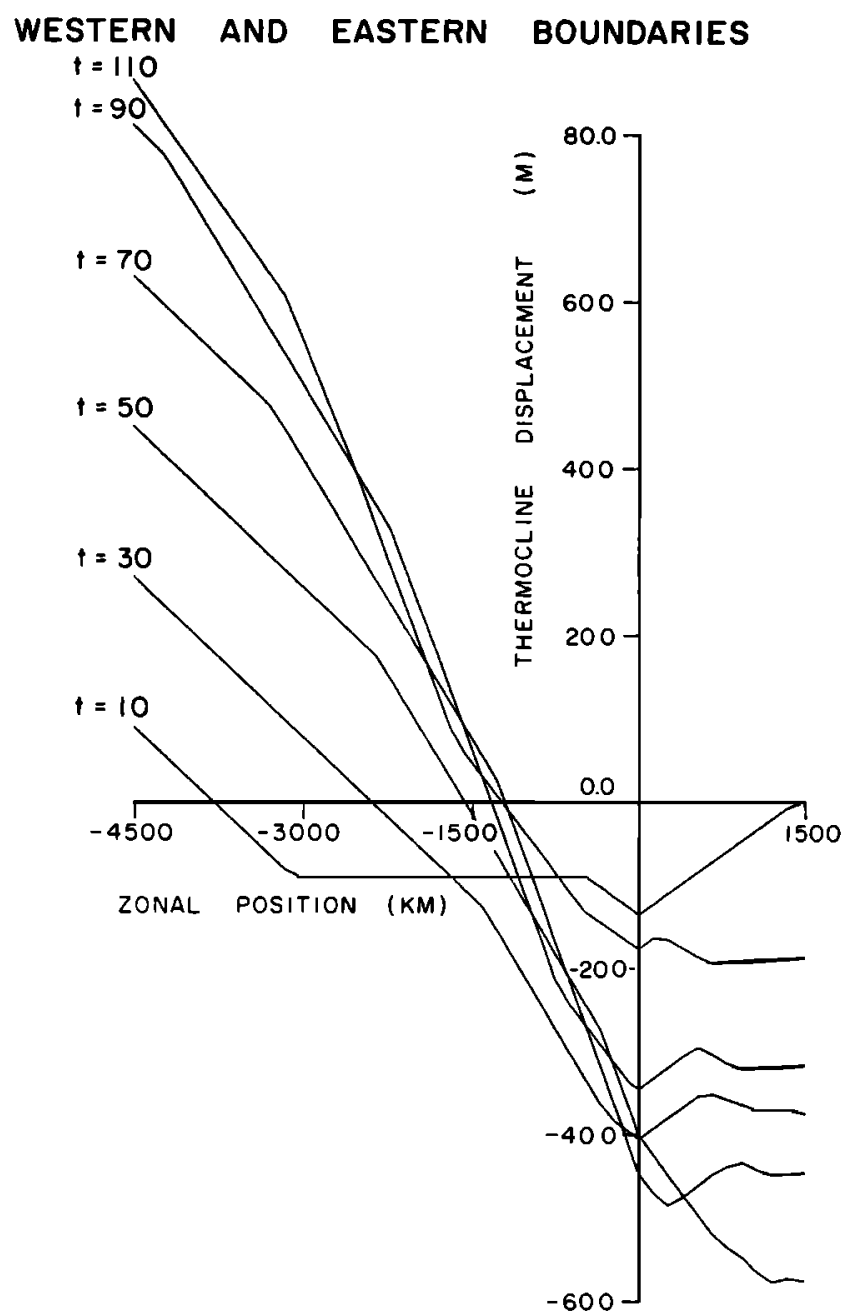

Fig. 7. Same as Figure 5 but with a western boundary at $-4500 \mathrm{~km}$ and an eastern boundary at $+1500 \mathrm{~km}$.

adjusted thermocline for this relatively simple case of switched on uniform easterly winds within a forced region, we now sample time series of thermocline displacement at specific longitudes to compare with actual observations in the equatorial Atlantic during 1983 and to discuss the integral nature of the response. Time series sampled at $28^{\circ} \mathrm{W}, 15^{\circ} \mathrm{W}$, $5^{\circ} \mathrm{W}$, and $0^{\circ} \mathrm{W}$ for the unbounded, western bounded, and both western and eastern bounded basins are shown in Figure 8 . The $28^{\circ} \mathrm{W}$ and $15^{\circ} \mathrm{W}$ locations are within the forced region, the $5^{\circ} \mathrm{W}$ location is at the eastern terminus of the forced region, and the $0^{\circ} \mathrm{W}$ location is outside the forced region. Each change in slope corresponds to a wave front passage. At $28^{\circ} \mathrm{W}$ the initial upwelling response is the sum of the forced Kelvin and Rossby wave responses. Both of these have westward velocity components due to the easterly winds, but the Kelvin wave is an upwelling wave while the Rossby wave is a downwelling wave. After passage of the Kelvin wave response generated between $28^{\circ} \mathrm{W}$ and the western extreme of the forced region, all that is left to influence the thermocline is the Rossby wave response. Consequently, downwelling takes hold until the Rossby wave response generated between $28^{\circ} \mathrm{W}$ and the eastern extreme of the forced region passes, leaving the thermocline at $28^{\circ} \mathrm{W}$ in equilibrium with the wind stress. To an observer fixed at a given longitude, the total thermocline displacement

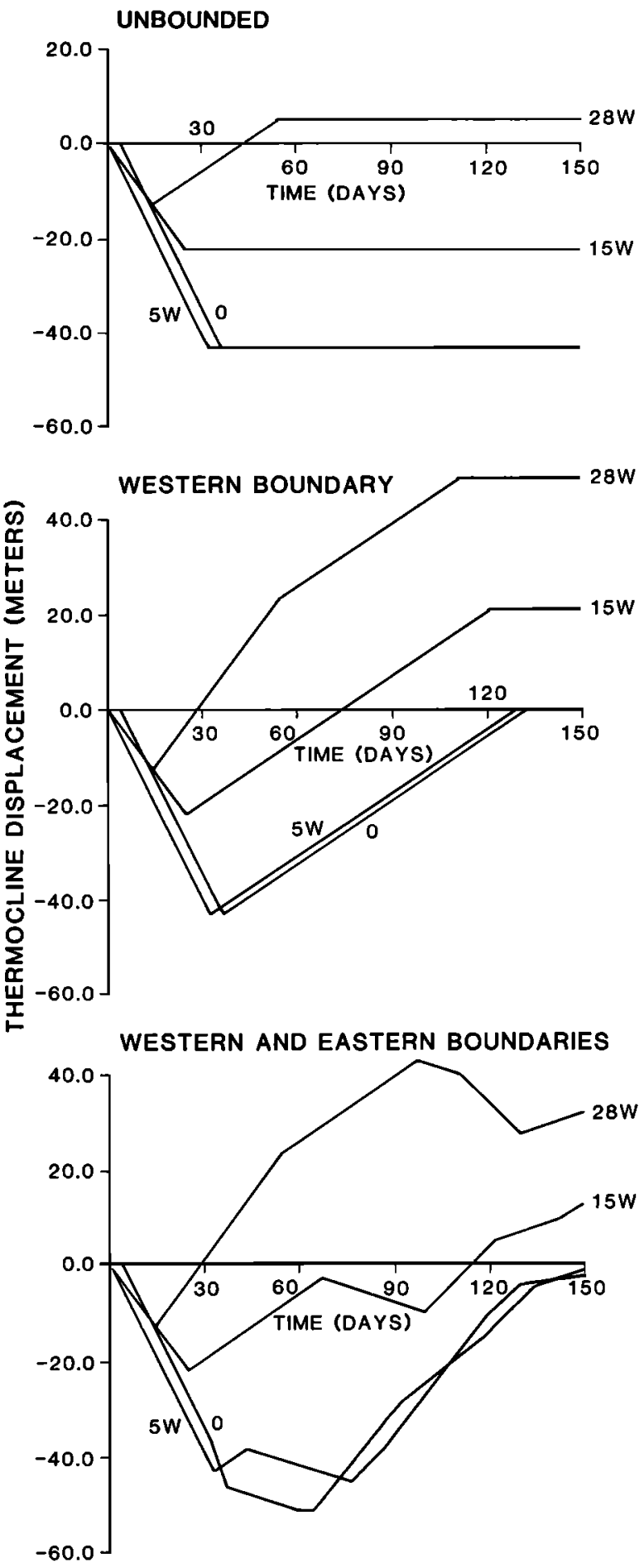

Fig. 8. Thermocline displacement as a function of time sampled at model positions corresponding to $28^{\circ} \mathrm{W}, 15^{\circ} \mathrm{W}, 5^{\circ} \mathrm{W}$, and $0^{\circ}$ for unbounded, western bounded, and both western and eastern bounded basins for the case of instantaneously switched on easterlies with uniform stress of $0.5 \mathrm{dyne} / \mathrm{cm}^{2}$ between $46^{\circ} \mathrm{W}$ and $5^{\circ} \mathrm{W}$.

corresponds to the integral of the Kelvin wave response from that point westward, since Kelvin waves propagate eastward, and the integral of the Rossby wave response from that point eastward, since long Rossby waves propagate westward. This integral nature becomes clear as we proceed to points further east. At $15^{\circ} \mathrm{W}\left(10^{\circ}\right.$ from the eastern and $31^{\circ}$ from the western extremes of the forced region, respectively) the Kelvin and Rossby wave integrals attain their steady 
values at essentially the same time, so rather than an upwelling/downwelling sequence, the entire response is an upwelling one. At $5^{\circ} \mathrm{W}$ there is no Rossby wave response, so again the entire response is upwelling and at a more rapid rate than at points to the west. Beyond $5^{\circ} \mathrm{W}$, at points further east and outside the forced region, an observer would see the propagation of a pulse without change in form which was generated within the forced region. Thus we may distinguish between integral responses dependent upon longitudinal position within the forced region and propagation without change in form outside the forced region.

Addition of a western boundary modifies the results, since the forced downwelling Rossby wave response reflects as a downwelling Kelvin wave there. At $28^{\circ} \mathrm{W}$ the sequence begins as before with upwelling corresponding to the sum of the forced Kelvin and Rossby wave responses. Concurrent with attainment of the full forced Kelvin wave integral the reflected downwelling Kelvin wave arrives, so the subsequent downwelling proceeds at a more rapid rate than in the unbounded case. Downwelling continues at a slower rate after the entire forced Rossby wave integral is attained, since the response at that time is entirely the reflected Kelvin wave. The change in character of the response going eastward to $15^{\circ} \mathrm{W}$ due to its integral nature is clear. Initial upwelling arises from the sum of the forced Kelvin and Rossby wave integrals. These integrals reach their steady values at the same time, concurrent with the arrival of the reflected Kelvin wave which then brings the thermocline to its steady value. At $5^{\circ} \mathrm{W}$ and $0^{\circ} \mathrm{W}$ the sequence is pure forced Kelvin wave response followed by pure reflected Kelvin wave to the steady value of zero displacement as discussed earlier.

The forced and reflected Kelvin waves incident upon an eastern boundary reflect as a suite of Rossby waves of higher gender. For example, at $28^{\circ} \mathrm{W}$ the slope change occurring around day 100 is due to the arrival of a first mode upwelling Rossby wave resulting from the reflection of the forced upwelling Kelvin wave response. This is followed by the first-mode Rossby wave alone, the sum of the first- and third-mode Rossby waves, and so on. The important point here is in the comparison between $5^{\circ} \mathrm{W}$ and $0^{\circ} \mathrm{W}$. The propagation of a distinct wave pulse without change in form is no longer possible. Given the width of the equatorial Atlantic relative to its zonal wind forced region a "far field" unaffected by direct forcing or reflections does not exist.

\section{Case B: Uniform Easterly Wind Stress With Linear Growth in Time to a Steady Value}

In this case we maintain the same spatial distribution of zonal wind stress as in case $A$, but rather than switch the wind on instantaneously to its steady value of $0.5 \mathrm{dyn} / \mathrm{cm}^{2}$, we allow for one month of linear growth to this value as depicted in Figure $4 a$. The analytical form of the forcing function is

$$
\begin{array}{r}
\tau, y, t)=r \exp \left(-y^{2} / 2\right)\left[\begin{array}{r}
\frac{t}{T} H(t)-\frac{t-T}{T} H(t-T) \\
\cdot[H(x)-H(x+L)]
\end{array}\right.
\end{array}
$$

where $r$ and $L$ are the easterly wind stress amplitude and fetch as before and $T$ is the growth time chosen here to be $\mathbf{3 0}$ days. The thermocline displacement responses on the equator at $28^{\circ} \mathrm{W}, 15^{\circ} \mathrm{W}, 5^{\circ} \mathrm{W}$, and $0^{\circ} \mathrm{W}$ for the unbounded,
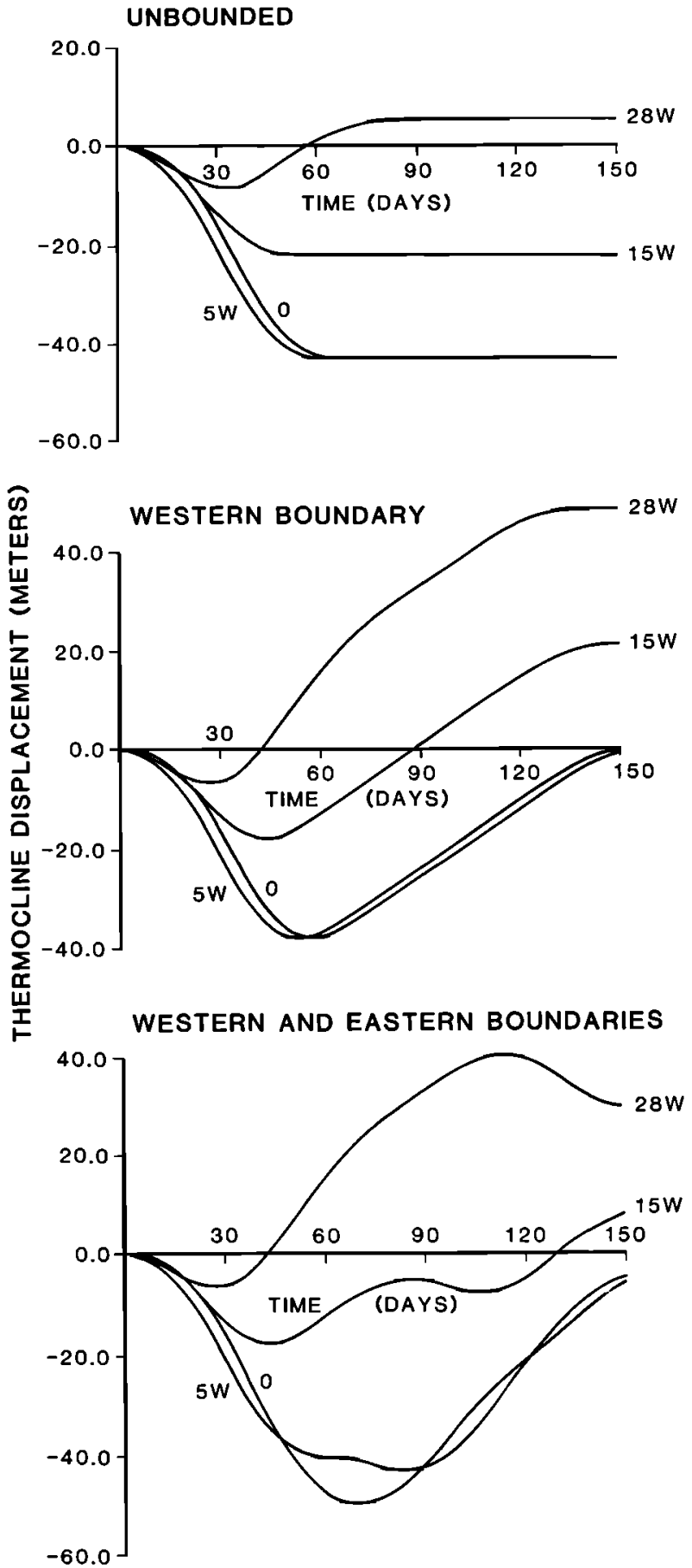

Fig. 9. Same as Figure 8 but for the case of easterlies increasing linearly over 1 month to a value of $0.5 \mathrm{dyne} / \mathrm{cm}^{2}$ uniformly between $46^{\circ} \mathrm{W}$ and $5^{\circ} \mathrm{W}$.

western bounded, and both western and eastern bounded basins are shown in Figure 9. These results are very similar to those of Figure 8, and as a check upon the calculation, the steady values are identical. Both the timing of the thermocline adjustment and the shape of the time series appear much more realistic with linear growth in the manner observed. Owing to the integral nature of the response, winds uniform in $x$ and linear in $t$ yield thermocline displacements quadratic in $t$, hence the smooth sigmoidal shapes as opposed to straight lines previously. The principal features of interest are evident. For the western boundary only, points 
furthest to the east within the wind-forced region exhibit the longest lived and largest upwelling response before giving way to downwelling due to the reflected Kelvin wave from the western boundary. This reflection enters the solution before growth is complete, so the upwelling is somewhat reduced from that of case $A$. Points further east beyond the wind-forced region exhibit propagation without change in form. Addition of an eastern boundary again mitigates against propagation without change in form by the distorting effect of reflected Rossby waves. Changes in curvature of the time series have the same interpretation as in case A but, since the curves are smooth, it is more difficult to pick each one out, and that is why we reviewed the simplest case first.

\section{Case C: Nonuniform Easterly Wind Stress With Linear Growth in Space and Time}

Referring back to Figure $4 b$, we now allow the easterlies to grow linearly in time to a steady value over 1 month while maintaining a uniform zonal wind stress gradient from zero at $5^{\circ} \mathrm{W}$ to a maximum at $46^{\circ} \mathrm{W}$. Rather than $0.5 \mathrm{dyn} / \mathrm{cm}^{2}$ as a maximum stress, we now choose $1.0 \mathrm{dyn} / \mathrm{cm}^{2}$ to keep the zonal integral of the wind stress constant, thereby keeping the steady values of thermocline displacement at the eastern extreme of the wind-forced region the same as before.

The analytical form of the forcing function is

$$
\begin{gathered}
\tau(x, y, t)=-r \exp \left(-y^{2} / 2\right) x\left[\frac{t}{T} H(t)-\frac{t-T}{T} H(t-T)\right] \\
\cdot[H(x)-H(X+L)]
\end{gathered}
$$

where $r=0.0047$ corresponding to a stress of $1 \mathrm{dyn} / \mathrm{cm}^{2}$ at the western boundary after 30 days and with all other parameters the same as before.

Results of case $\mathrm{C}$ for the unbounded, western bounded, and both western and eastern bounded basins are shown in Figure 10. The timing of the sequence of events leading to an adjusted thermocline is very similar to that of case B. Points furthest to the east within the wind-forced region again exhibit the longest lived and largest upwelling response. The spatial nonhomogeneity in easterly wind stress affects the relative amount of upwelling and downwelling at a particular longitude by changing the integral Kelvin and Rossby wave responses, as is evident from a comparison of Figures 9 and 10. Therefore the thermocline displacement at any point within the wind-forced region depends upon the zonal distribution of wind stress within the entire wind-forced region. For example, in an unbounded basin, without reflected waves, upwelling and downwelling at a given location are determined solely by Kelvin and Rossby waves generated to the west and east of that point, respectively. In the present configuration, with ever larger wind stress to the west, the Kelvin wave response at a given point within the windforced region will exceed the Rossby wave response relative to the uniform wind stress case and consequently there will be larger upwelling.

\section{Response to a Sequential Decrease and Increase in EAsterly Wind STRESS}

In Figure 1 we observed that prior to the seasonal intensification of easterly wind stress there existed a short lived relaxation event. Continuing along the same vein as the

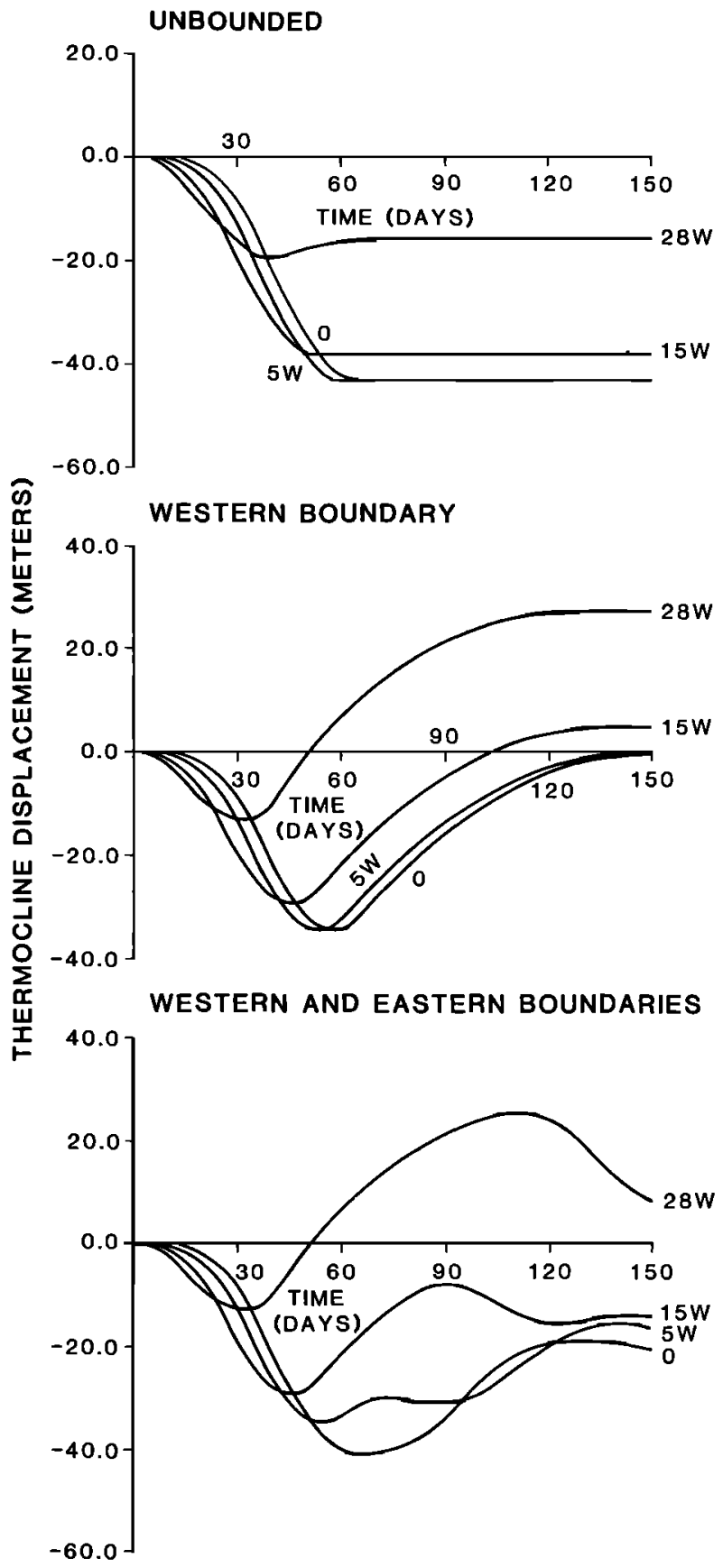

Fig. 10. Same as Figure 8 but for the case of easterlies increasing linearly in time and space over 1 month with a value of zero at $5^{\circ} \mathrm{W}$ and a maximum of $1 \mathrm{dyne} / \mathrm{cm}^{2}$ at $46^{\circ} \mathrm{W}$.

previous section, we will study the response of a bounded equatorial ocean basin to a sequential relaxation/intensification event using the forcing function and basin geometry depicted in Figure 11. Since a relaxation in easterlies is the same as an intensification in westerlies, the sequence consists of switching on westerlies with linear growth in $x$ and $t$ from a value of zero at $5^{\circ} \mathrm{W}$ to a maximum at the western boundary at $46^{\circ} \mathrm{W}$ attained after 10 days and then adding to this easterlies with the same spatial form and with temporal growth to a maximum value after $\mathbf{3 0}$ days. The combined relaxation/intensification event in easterly wind stress then consists of 10 days of relaxation followed by 30 days of intensification with the relaxation to intensification ampli- 


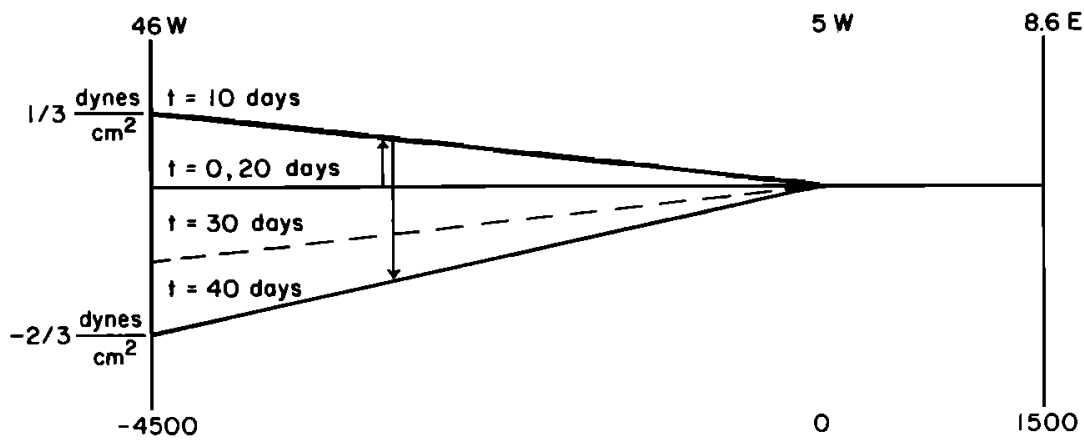

ZONAL POSITION (KM)

Fig. 11. Model geometry and zonal wind stress forcing function for the relaxation/intensification event. Wind stress varies linearly both in time and space from zero at $5^{\circ} \mathrm{W}$ to a maximum at $46^{\circ} \mathrm{W}$ beginning with westerlies growing to 0.33 dyne $/ \mathrm{cm}^{2}$ over 10 days followed by easterlies growing to $-0.67 \mathrm{dyne} / \mathrm{cm}^{2}$ over the next 30 days after which the winds remain steady.

tude ratio being 1 to 3 , roughly in accordance with what was observed in 1983.

The western and eastern bounded basin response on the equator is shown as a function of longitude and time in Figure 12. Contours are of thermocline displacement in meters with a contour interval of $2.5 \mathrm{~m}$. Positive and negative values correspond to an upper layer thickness which is increased or decreased from its unforced state. Thus positive rate of change with time corresponds to downwelling and conversely for upwelling. Time series sampled from Figure 12 at $28^{\circ} \mathrm{W}$ and $15^{\circ} \mathrm{W}$ are shown in Figure 13. Downwelling is observed to commence over the entire wind-forced domain coincident with the relaxation onset. Owing to the integral nature of the forced wave responses, this initial downwelling event has the appearance of propagating eastward but not at the model Kelvin wave speed and not without change in form. Note that although the responses begin simultaneously at both longitudes, downwelling continues over a longer duration and with larger magnitude at $15^{\circ} \mathrm{W}$ than at $28^{\circ} \mathrm{W}$ because the domain of integration for the downwelling response at $15^{\circ} \mathrm{W}$ is larger. The temporal separation between the downwelling peaks at these longitudes corresponds to the additional time that it takes for the integral response at $15^{\circ} \mathrm{W}$ to obtain its maximum value over that at $28^{\circ} \mathrm{W}$. This time differs from the model Kelvin wave propagation time, since the total forced wave response also includes the Rossby wave and, more importantly, the responses to increased easterlies which

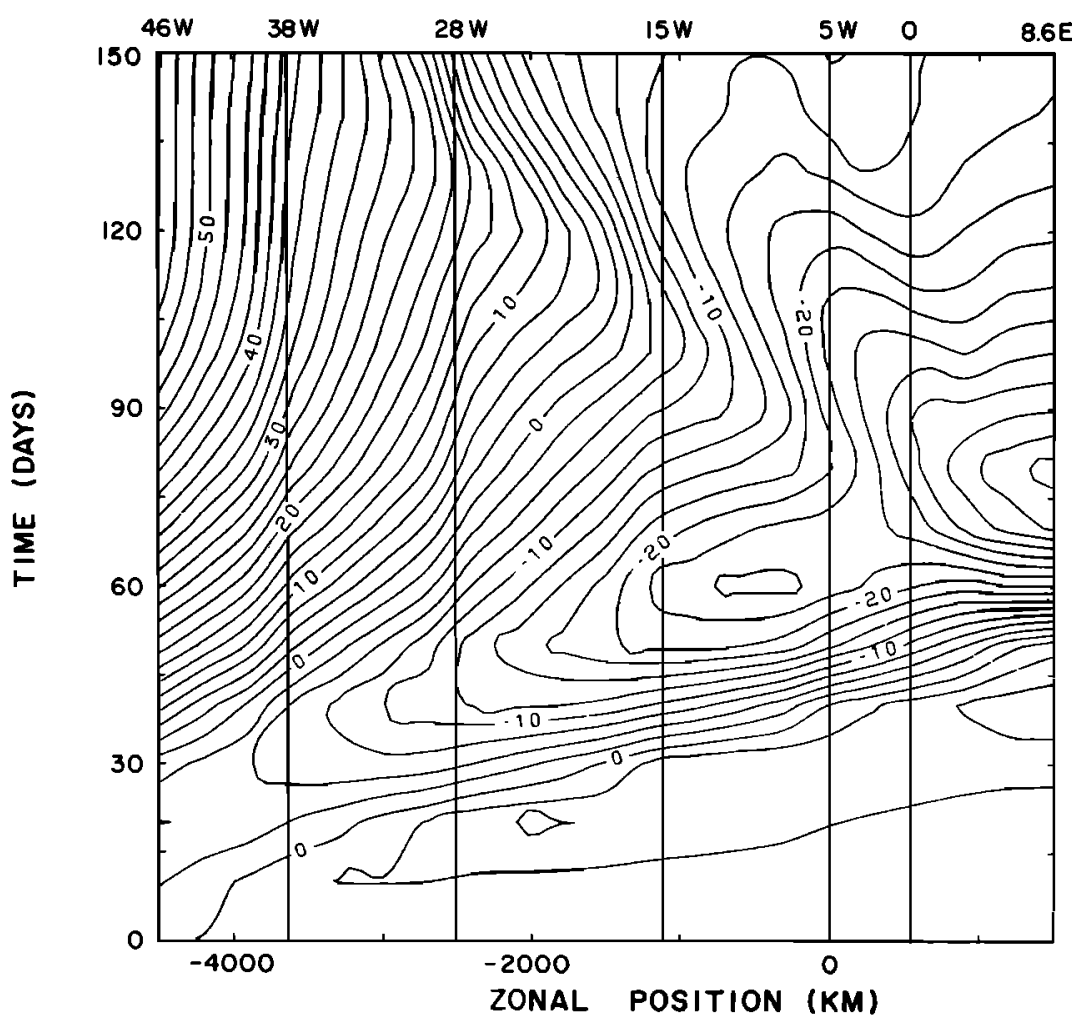

Fig. 12. Thermocline displacement as a function of longitude and time for the forcing function of Figure 11. Contour interval is $2.5 \mathrm{~m}$. Positive denotes increasing upper layer thickness, and conversely therefore positive temporal gradient corresponds to downwelling and negative temporal gradient corresponds to upwelling. 


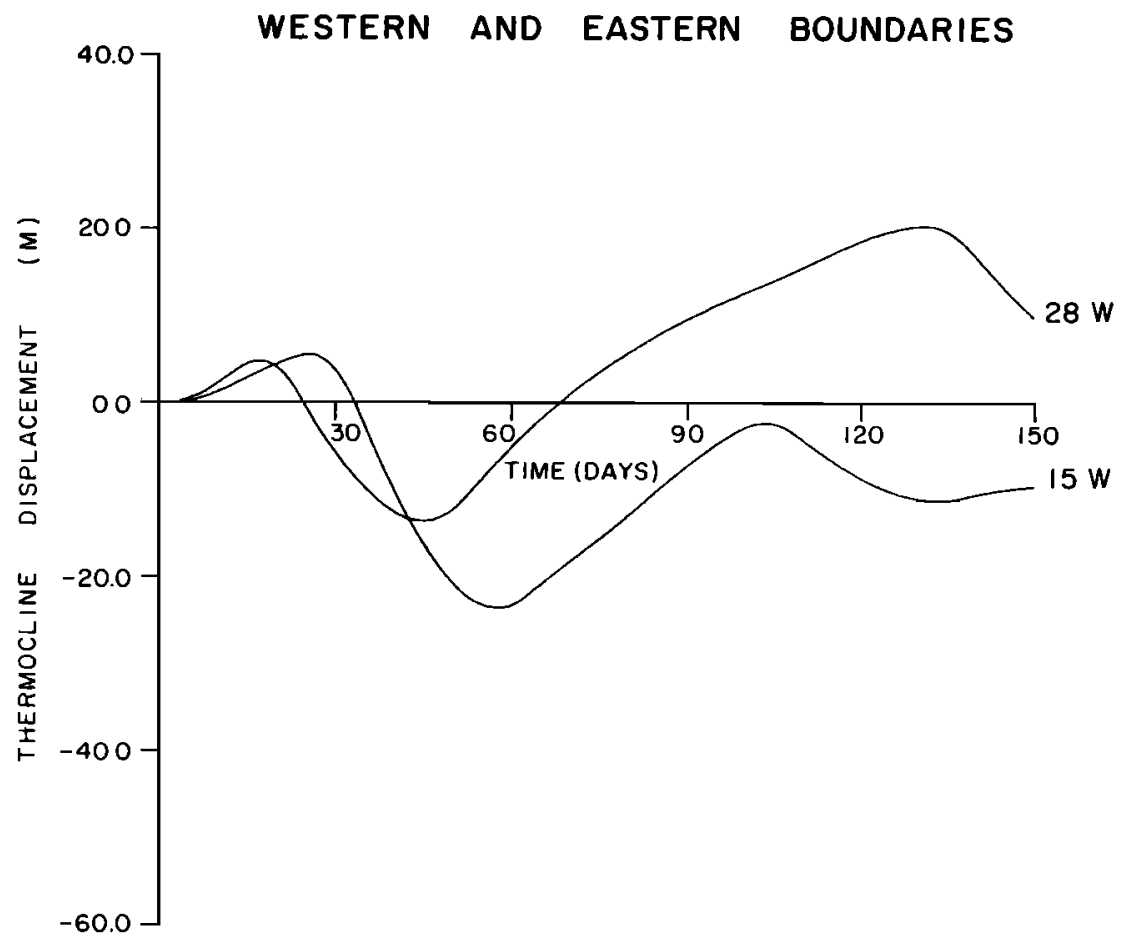

Fig. 13. Time series of thermocline displacement sampled from Figure 12 at $28^{\circ} \mathrm{W}$ and $15^{\circ} \mathrm{W}$.

begin prior to completion of the relaxation responses. Sampling Figure 12 at several longitudes (only two of which are shown in Figure 13) yields a sequence of peaks qualitatively similar to the inverted echo sounder records of Figure 2. The peak at $38^{\circ} \mathrm{W}$ is the smallest, since its integral response is the smallest and peaks at successive longitudes to the east generally increase in width and height depending upon the interference of the relaxation and subsequent intensification responses. Calculating apparent propagation speeds between successive peaks gives values ranging from $1.9 \mathrm{~m} / \mathrm{s}$ to $2.2 \mathrm{~m} / \mathrm{s}$ with a mean of $2.0 \mathrm{~m} / \mathrm{s}$, all of which differ significantly from the model reduced gravity Kelvin wave speed of 1.6 $\mathrm{m} / \mathrm{s}$.

As the easterlies intensify, the downwelling relaxation event is replaced by upwelling, and from there onward the sequence of events in the central portion of the basin proceeds essentially as discussed in the previous section. Upwelling occurs over a longer duration and with larger magnitude to the east, giving way to downwelling upon the arrival of the reflected Kelvin wave from the western boundary. Perceiving individual wave speeds becomes increasingly more difficult with time as the interference of forced and reflected waves makes the mixture of waves too complex, as has been noted previously by Cane and Sarachik [1981] and Philander and Pacanowski [1981a].

The interference pattern between the relaxation and subsequent intensification events in the eastern portion of the basin is particularly interesting. Upwelling in the Gulf of Guinea, both along the equator and along the African coast, is a prominent feature of the equatorial Atlantic's annual cycle. Moore et al. [1978], Adamec and O'Brien [1978], Servain et al. [1982], and McCreary et al. [1983] suggest a remote forcing mechanism originating in the western side of the basin with upwelling propagating along the equatorial waveguide and then poleward along the coast. Historical subsurface temperature data analyses by Houghton [1983] showing that upwelling along the equator has a maximum value between $0^{\circ} \mathrm{W}$ and $10^{\circ} \mathrm{W}$ and separate from the African coast, while not arguing against the above mechanism, does suggest a more involved explanation. That this region is the origin of easterly wind stress over the western two thirds of the basin is germane. Weisberg and Tang [1983] showed that upwelling at the origin is maximum for the case of easterlies with westward expanding fetch in an unbounded basin, since the origin has the largest integral response. This would also occur with easterlies switched on over a fixed fetch but only for a limited time (Figure 5). This time is further decreased by the addition of boundaries due to reflections (Figures 6 and 7). Thus maintaining a midocean region of maximum upwelling separate from the coast requires additional ingredients. Not all of these ingredients need be associated with easterly wind stress forcing within the equatorial waveguide. For example, Philander and Pacanowski $[1981$ b] show that cross-equatorial southerly winds as occur over the eastern portion of the basin are effective in producing coastal upwelling along the eastern boundary to the south of the equator, advecting this upwelled water somewhat north of the equator and propagating it westward into the basin interior via Rossby waves. The net result is an accentuated coastal upwelling decreasing in magnitude to the west, but this does not explain the midocean maximum. One possible explanation is provided by the interference patterns of the forced and reflected long-wave responses. The combined response to relaxing and subsequently intensifying easterlies results in an interference between the forced upwelling Kelvin wave response due to the intensification and the reflected downwelling first-mode Rossby wave due to the relaxation. These add destructively in the Gulf of Guinea, separating a local maximum upwelling region centered upon $10^{\circ} \mathrm{W}$ in Figure 12 from the coast. The duration of this particular pattern depends upon the duration of the relaxation response which for the present calculation is short. 


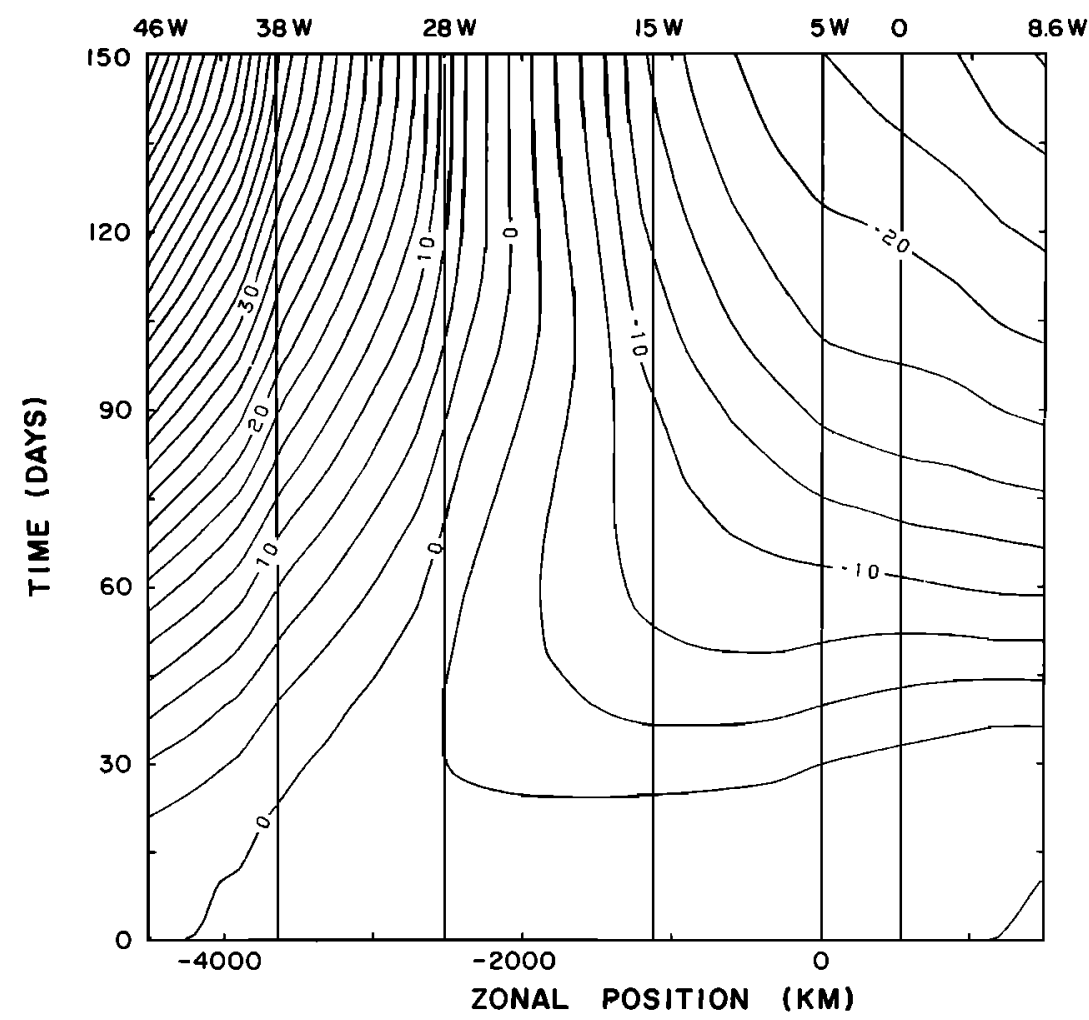

Fig. 14. Same as Figure 12 but for the easterly forcing function of Figure $4 b$ with growth time of 5 months.

Later on in the evolution of the forced response to increased easterlies, the reflected Rossby wave pattern again results in equatorial upwelling separate from the coast, and this can be further accentuated by adding (not shown) a westerly wind stress to the east of the origin as suggested by the data of Picaut [1983].

\section{Discussion}

The development of the equatorial thermocline's response both within and outside an easterly wind forced region has been reviewed. At any point within the wind-forced region the response arises as the integral over the entire region, while the response outside the forced region arises from wave propagation from the forced region. Thus we discriminate between integral responses with change in form and wave pulse propagation. For an equatorial ocean basin the size of the Atlantic, meridional boundaries are too close to the region of annual scale forcing to allow for wave packets to develop fully before being distorted by boundary reflections. This finding for the Atlantic is in contrast with the Pacific Ocean observation of Knox and Halpern [1982] where an annual eastward transport surge did appear to propagate between $152^{\circ} \mathrm{W}$ and $110^{\circ} \mathrm{W}$ without change in form. Both results are compatible, however, if the forcing for the latter case occurred primarily to the west of $152^{\circ} \mathrm{W}$ as those authors suggested.

As either an initial value or a periodically forced problem, the character of the thermocline response depends upon the propagation time for waves to traverse the region relative to the time scale of the forcing [e.g., Cane and Sarachik, 1981; Philander and Pacanowski, 1981a], since it is the waves that bring the pressure gradient into balance with the forcing. For impulsive forcing, waves will appear distinctly in the solution, while for more slowly developing forcing, the ocean will attain an equilibrium with the wind stress over a time scale comparable with its variation and waves will not be discernible. As an example, Figure 14 shows the thermocline displacement as a function of longitude and time for the easterly wind stress distribution of Figure $4 b$ but with a time scale of $T=5$ months. Individual waves are not observed, and by the time the wind stress has fully developed, the equatorial thermocline has practically reached equilibrium.

In the equatorial Atlantic there are times of the year when wavelike behavior should be evident corresponding to the times of rapid change and other times of year when the zonal pressure gradient should appear in balance with the wind stress (as shown by Katz et al. [1977]) corresponding to more slowly varying changes in wind stress. This explains why models of the tropical Atlantic forced using slowly varying climatological monthly wind fields such as the single mode reduced gravity model of Busalacchi and Picaut (1983) and the multiple mode reduced gravity model of $d u$ Penhoat and Treguier [1984] can be very successful at describing the adjusted states but not as successful describing the transitions along the equator that give rise to these states.

\section{SumMary}

Variations of the thermocline were observed along the equator from February to September 1983 as part of the SEQUAL experiment. Following a rapid increase in easterly wind stress, a sequence of upwelling and downwelling occurred as the zonal pressure gradient adjusted to balance the increased winds. Both the duration and magnitude of these upwelling and downwelling responses increased to the east. This zonal inhomogeneity was shown to be consistent with the integral nature of the ocean's response within a wind-forced region. Analytical calculations were performed 
using a linear, adiabatic, equatorial $\beta$ plane, reduced gravity model driven by a hierarchy of easterly winds. Pertinent findings are given below. First, the evolution of the thermocline response along the equator is dependent upon longitudinal position within the wind-forced region, since the forced Kelvin (Rossby) wave portion of the response is an integral from that point westward (eastward). Second, these forced responses will continue to grow until their integrals are fully developed, which depends upon position within the forced region and wave speeds. For annual scale forcing in the equatorial Atlantic, boundary reflections come into play before these integrals are fully developed. Consequently, nondispersive wave pulses cannot propagate without change in form even outside the region of wind forcing. Third, the apparent propagation speeds of downwelling and upwelling sequences within the wind-forced region differ significantly from the prescribed baroclinic wave speeds. Apparent propagation speeds may be slower or faster depending upon the growth parameters of the wind-forcing function. Fourth, the interference pattern between responses to relaxing easterlies followed by intensifying easterlies may be a factor in separating the region $0^{\circ}-10^{\circ} \mathrm{W}$ from the African coast as one of maximum upwelling.

The behavior of a physical system in adjusting to a forcing function is dependent upon the natural time scales of the system relative to the time scales of the forcing. In the equatorial Atlantic Ocean which undergoes both rapid, almost impulsive, variations in easterly wind stress and more gradual variations, the equatorial thermocline goes through periods when the natural wavelike responses appear prominent and periods when the responses appear in equilibrium. Since observations of these responses are generally made within the wind-forced region, knowledge of both the spatial and temporal properties of the forcing function is essential in interpreting the ocean's response.

Acknowledgments. Support for this work was provided by the Oceanography Section, National Science Foundation, under grant OCE-8211848. J. Hickman assisted with the computations, T. Clay and D. Williams prepared the figures, and D. Bombard and B. Neville prepared the text.

\section{REFERENCES}

Adamec, D., and J. J. O'Brien, The seasonal upwelling in the Gulf of Guinea due to remote forcing, J. Phys. Oceanogr., 8, 1050-1060, 1978.

Busalacchi, A. J., and J. Picaut, Seasonal variability from a model of the tropical Atlantic Ocean, J. Phys. Oceanogr., 13, 1564-1588, 1983.

Cane, M., and E. S. Sarachik, Forced baroclinic ocean motions, I, The linear equatorial unbounded case, J. Mar. Res., 34, 629-665, 1976.

Cane, M., and E. S. Sarachik, Forced baroclinic ocean motions, II, The linear equatorial bounded case, J. Mar. Res., 35, 395-432, 1977.

Cane, M., and E. S. Sarachik, The response of a linear baroclinic equatorial ocean to periodic forcing, J. Mar. Res., 39, 651-693, 1981.

Cane, M., and E. S. Sarachik, Seasonal heat transport in a forced equatorial baroclinic model, J. Phys. Oceanogr., 13, 1744-1746, 1983.

du Penhoat, Y., and A. M. Treguier, Sea surface dynamic height topography and the North Equatorial Countercurrent as inferred from a linear model, Geophys. Res. Lett., 11, 799-801, 1984.
Garzoli, S., and E. J. Katz, Winds at St. Peter and St. Paul rocks during the first SEQUAL year, Geophys. Res. Lett., $11,715-718$, 1984.

Hastenrath, S., and P. J. Lamb, Climatic Atlas of the Tropical Atlantic and Eastern Pacific Ocean, 25 pp. and 9 charts, The University of Wisconsin Press, Madison, 1977.

Hellerman, S., Charts of the variability of the wind stress over the tropical Atlantic, Deep Sea Res., 26, suppl. II, 63-75, 1979.

Houghton, R. W., Seasonal variation of the subsurface thermal structure in the Gulf of Guinea, J. Phys. Oceanogr., 13, 20702081, 1983.

Hurlburt, H. E., J. C. Kindle, and J. J. O'Brien, A numerical simulation of the onset of El Niño, J. Phys. Oceanogr., 6, 621631, 1976.

Katz, E. J., Basin wide thermocline displacements along the equator of the Atlantic in 1983, Geophys. Res. Lett., 11, 729-732, 1984.

Katz, E. J., et al., Zonal pressure gradient along the equatorial Atlantic, J. Mar. Res., 35, 293-307, 1977.

Knox, R. A., and D. Halpern, Long range Kelvin wave propagation of transport variations in Pacific Ocean equatorial currents, $J$. Mar. Res., 40, suppl., 329-339, 1982.

McCreary, J. P., Eastern tropical ocean response to changing wind systems: With application to El Niño, J. Phys. Oceanogr., 6, 632645, 1976.

McCreary, J. P., J. Picaut, and D. W. Moore, Effects of remote annual forcing in the eastern tropical Atlantic Ocean, J. Mar. Res., 42, 45-81, 1983.

Moore, D. W., and S. G. H. Philander, Modelling of the tropical oceanic circulation, in The Sea, vol. 6, edited by E. Goldberg et al., pp. 319-361, Wiley-Interscience, New York, 1977.

Moore, D. W., P. Hisard, J. P. McCreary, J. Merle, J. J. O'Brien, J. Picaut, J. M. Verstraete, and C. Wunsch, Equatorial adjustments in the eastern Atlantic, Geophys. Res. Lett., 5, 637-640, 1978.

O'Brien, J. J., and H. E. Hurlburt, Equatorial jet in the Indian Ocean: Theory, Science, 184, 1075-1077, 1974.

Payne, R., Surface wind measurements in SEQUAL 1, Geophys. Res. Lett., 11, 719-721, 1984.

Philander, S. G. H., and R. C. Pacanowski, The generation and decay of equatorial currents, J. Geophys. Res., 85, 1123-1136, 1980.

Philander, S. G. H., and R. C. Pacanowski, Response of equatorial oceans to periodic forcing, J. Geophys. Res., 86, 1903-1916, $1981 a$.

Philander, S. G. H., and R. C. Pacanowski, The oceanic response to cross equatorial winds (with application to upwelling at low latitudes), Tellus, 33, 204-210, $1981 b$.

Picaut, J., Propagation of the seasonal upwelling in the eastern equatorial Atlantic, J. Phys. Oceanogr., 13, 18-37, 1983.

Servain, J., J. Picaut, and J. Merle, Evidence of remote forcing in the equatorial Atlantic Ocean, J. Phys. Oceanogr., 12, 457-463, 1982.

Tang, T. Y., and R. H. Weisberg, On the equatorial Pacific response to the 1982/1983 El Niño-Southern Oscillation event, J. Mar. Res., 42, 809-829, 1984.

Weisberg, R. H., Seasonal adjustments in the equatorial Atlantic during 1983 as seen by surface moorings, Geophys. Res. Lett., 11, 733-735, 1984.

Weisberg, R. H., and T. Y. Tang, Equatorial ocean response to growing and moving wind systems with application to the Atlantic, J. Mar. Res., 41, 461-486, 1983.

Yoshida, K., A theory of the Cromwell current (the Equatorial Undercurrent) and of the equatorial upwelling-An interpretation in a similarity to a coastal circulation, J. Oceanogr. Soc. Jpn., 15, 1-13, 1959.

T. Y. Tang and R. H. Weisberg, Department of Marine Science, University of South Florida, 140 Seventh Avenue South, St. Petersburg, FL 33701.

(Received September 27, 1984, accepted February 25, 1985.) 